\title{
Postural balance and fall risk in patients with systemic sclerosis: A cross-sectional study
}

\author{
Hazal Yakut $^{1} \mathbb{D}$, Sevgi Özalevli² ${ }^{\mathbb{D}}$, Ahmet Merih Birlik $^{3}$ \\ ${ }^{1}$ Department of Physical Therapy and Rehabilitation, Dokuz Eylül University, Institute of Health Sciences, Izmir, Turkey \\ ${ }^{2}$ Dokuz Eylül University, School of Physical Therapy and Rehabilitation, Izmir, Turkey \\ ${ }^{3}$ Department of Internal Medicine, Division of Rheumatology, Dokuz Eylül University Faculty on Medicine, Izmir, Turkey
}

\begin{abstract}
Objectives: This study aims to assess postural balance, fall risk, and the relationship of these parameters with disease-related factors in patients with systemic sclerosis (SSc).

Patients and methods: Thirty patients with SSC (6 males, 24 females; mean age $51.1 \pm 10.6$ years; range 35 to 65$)$ and 30 healthy subjects (6 males, 24 females, mean age 52.4 \pm 8.7 years; range 35 to 65 ) matched for age, sex and body mass index were included in this cross-sectional study conducted between September 2018 and November 2019. Postural balance was measured with Biodex Balance System ${ }^{\text {TM }}$ (Biodex-BS), Berg Balance Scale (BBS), and Timed Up and Go (TUG) test. Individuals' history of falls in the past year, functional capacity, lower limb muscles strength, pulmonary function, respiratory muscle strength, diffusion capacity, and dyspnea severity were evaluated.

Results: The SSc group had postural balance impairment and a higher fall frequency than the control group. The SSc group had significantly higher sway index on postural stability $(0.6 \pm 0.5)$, lower directional control score $(42.1 \pm 8.0)$, and longer test duration $(51.8 \pm 11.8)$ on limit of stability of Biodex-BS, lower BBS score (51.5 \pm 4.9 ), and longer test duration on TUG test $(8.3 \pm 2.7)$ than control group (all $p<0.05)$. Also, SSc group exhibited significantly lower functional capacity, limb muscles strength, pulmonary function, respiratory muscles strength, diffusion capacity, and higher dyspnea severity than control group (all $\mathrm{p}<0.05$ ). The postural balance and fall frequency of SSc patients were significantly associated with functional capacity, lower limb muscles strength, pulmonary function, respiratory muscle strength, diffusion capacity, and dyspnea severity.

Conclusion: Our results suggest that postural balance impairment and fall risk should be assessed as they appear to be important problems in patients with SSc. Furthermore, assessment of functional capacity, lower limb muscles strength, and lung involvement may highlight those with postural balance impairment and higher fall risk.

Keywords: Fall risk, lung involvement, muscle strength, postural balance, systemic sclerosis.
\end{abstract}

Systemic sclerosis (SSc) is a multi-systemic disease of unknown etiology characterized by damage to the vascular structures with increased collagen production and deposition in the skin, body systems, and internal organs. ${ }^{1}$ Although cutaneous involvement is one of the most prominent clinical features of SSc, it aggressively affects the kidneys, gastrointestinal tract, musculoskeletal and cardiopulmonary systems, eventually leading to extensive fibrosis. While 70 to $90 \%$ of patients have lung involvement such as interstitial lung disease (ILD) and pulmonary arterial hypertension (PAH), more than $80 \%$ of them have osteomioarticular system effects such as myositis, myopathy, and calcification of joints, tenosynovitis, and polyarthritis. ${ }^{2-4}$ Widespread

Received: May 27, 2020 Accepted: July 22, 2020 Published online: January 14, 2021

Correspondence: Hazal Yakut, MD. Dokuz Eylül Üniversitesi, Sağlık Bilimleri Enstitüsü, Fizik Tedavi ve Rehabilitasyon Anabilim Dalı, 35330 Balçova, İzmir, Türkiye. Tel: +90 507 - 4825877 e-mail: fzthazalyakut@outlook.com

Citation:

Yakut H, Özalevli S, Birlik AM. Postural balance and fall risk in patients with systemic sclerosis: A cross-sectional study. Arch Rheumatol 2021;36(2):167-175. 
weakness, increased muscle atrophy, skin sclerosis, loss of joint function, and increased enzyme creatine phosphokinase production may occur as a result of cutaneous and osteomioarticular system involvement, which may cause systemic muscle diseases and significant functional limitations in these patients. ${ }^{5}$ In addition to lung and osteomioarticular involvement, chronic inflammation and steroid consumption can be considered as the main risk factors for the development of muscle weakness and functional limitation in SSc. ${ }^{6}$ Along with muscle-joint abnormalities, changes in sensorimotor stimulation and posture can also be seen. Considering these various dysfunctions observed in SSc, it is often associated with autonomic dysfunctions and postural balance impairments. However, the number of studies evaluating postural balance in patients with $\mathrm{SSc}$ is limited and the results are controversial. Moreover, the possible mechanisms that may lead to postural balance impairment are still unknown. ${ }^{7,8}$

Postural balance is a complex mechanism that entails any stimulus and/or response interaction from the vestibular, visual, musculoskeletal, and somatosensory systems and the effector portion is related to postural control motor reactions. Any deterioration in these balance-related systems compromises the control of the postural balance through impaired integration and accuracy of sensory information and/or motor responses. As a result of the poor balance, the fall risk increases. ${ }^{9,10}$ The frequency of falls in many rheumatoid diseases is reported between 33 to $54 \%$. It is stated that factors such as sensitive and swollen joints, increased pain perception, drug side effects, decreased lower limb muscle strength, fatigue, decreased mobility, and impaired balance increase the fall risk in people with rheumatoid diseases. ${ }^{11}$ However, we did not find any study investigating the fall risk and its related factors in patients with SSc.

Maintaining postural balance and body orientation is essential for the performance of daily life physical activities and functional independence. ${ }^{12}$ Therefore, we strongly believe that postural balance and fall risk are important topics that should be investigated in patients with SSc. We hypothesized that patients with $\mathrm{SSc}$ would have postural balance impairments and higher fall risk regardless of their age due to their cutaneous, cardiopulmonary, and osteomioarticular manifestations. Therefore, in this study, we aimed to assess postural balance, fall risk, and the relationship of these parameters with disease-related factors in patients with SSc.

\section{PATIENTS AND METHODS}

This cross-sectional study was conducted at the School of Physical Therapy and Rehabilitation and Department of Rheumatology, Dokuz Eylul University, Faculty of Medicine, between September 2018 and November 2019. The inclusion criteria were a definite SSc according to the American College of Rheumatology/European League against Rheumatism ${ }^{13}$ by a specialist rheumatologist and being 35 years of age or more. Patients with musculoskeletal, neurological, visual, vestibular, somatosensory disease, and disability that might interfere with locomotion, patients who had orthopedic disorders or surgery limiting the balance assessment and using an assistive device for ambulation were excluded. They were asked to continue their regular medical treatment and to drop off if any unstable condition occurs during the study. Thus, a total of 30 patients with SSc (6 males, 24 females; mean age $51.1 \pm 10.6$ years; range 35 to 65 ) were included.

For the control group, 30 healthy volunteers (6 males, 24 females, mean age 52.4 48.7 years; range 35 to 65 ) were recruited from the Dokuz Eylul University, Faculty of Medicine employees. These participants did not show any evidence of disorders and/or disease (mental, neurological, visual, vestibular, somatosensory, cardiopulmonary, musculoskeletal, orthopedic or rheumatological). The study protocol was approved by the Dokuz Eylul University Ethics Committee (approval number: 2017/29-15). A written informed consent was obtained from each subject. The study was conducted in accordance with the principles of the Declaration of Helsinki.

Demographic data including age, sex, body mass index (BMI), disease data including duration of disease, subtype of disease, presence of ILD, PAH, Raynaud's phenomenon and smoking status, the consumption amount of tobacco (packet/year), and exercise habits were recorded at initial interview. Postural balance, history of falls, functional capacity, lower limb muscle 
strength, pulmonary function, respiratory muscle strength, diffusion capacity, and dyspnea severity were evaluated on the same day. Subjects were rested for 10 min between each assessment to prevent possible fatigue due to tests.

The Biodex Balance System ${ }^{\mathrm{TM}}$ (Biodex-BS) (Biodex Medical Systems, Inc., Shirley, NY, USA), Timed Up and Go (TUG) test, and the Berg Balance Scale (BBS) were used for balance assessment. The Biodex-BS is a valid, reliable, and objective method to assess static and dynamic balance. The Biodex-BS consists of a mobile platform and evaluates postural stability (PS) and Limit of Stability (LOS) Index. The PS calculates a Medial-Lateral Stability Index (MLSI), Anterior-Posterior Stability Index (APSI), and an Overall Stability Index (OSI). Higher scores show impaired balance and increased fall risk. LOS Index challenges patients to move and control their center of gravity in eight predetermined target positions while measuring the displacement of center of pressure in anteroposterior and mediolateral directions, the test duration, and overall percentage score. The overall percentage represents the amount of deviation from a straight pathway to the targets. Low scores are indicative of a poor neuromuscular control and impaired balance. Test duration reflects the total amount of time it took the individual to complete the test. Lower test duration reflected a better balance performance. ${ }^{14}$

The TUG test was used to assess physical performance, functional mobility, and gait speed. The test includes the time it takes for getting up from a chair, walking $3 \mathrm{~m}$, turning, and sitting again, which is recorded in seconds. ${ }^{15}$

The BBS is developed for the evaluation of functional balance and consists of 14 items. The total score ranges from 0 (unable to perform) to 4 points (normal performance) with the highest score of 56 while lower scores indicate worse balance. $^{16}$

The history of falls was assessed and recorded with simple questions such as whether the subject had fallen over the past year and how many times.

The six-minute walking test (6MWT) was performed using the methodology postulated by the American Thoracic Society (ATS) for functional capacity assessment. The walking distance was recorded in meters. In addition, the test was performed safely by measuring the oxygen saturations and heart rates of the participants. ${ }^{17}$

Muscle strength of lower limb was measured with a hand-held dynamometer (HHD, MicroFET ${ }^{\circledR}$, Hoggan Health Industries, Inc., UT, USA). The HHD records the peak force required to break an isometric contraction. Dominant side hip flexors, knee extensors ( $\mathrm{m}$. quadriceps femoris) and ankle extensors ( $\mathrm{m}$. tibialis anterior) were evaluated as kilogram-force. Patients were asked to continue the maximum isometric contraction for $5 \mathrm{sec}$ at the designated test position (test position for hip flexors: the thigh was lifted by $10^{\circ}$ from the seat, for the knee extensor: in the seated position with $90^{\circ}$ knee flexion, the lower leg fell to the ground and for ankle extensor: heel on the ground during dorsiflexion). For each muscle group, three measurements were taken and there was a 1-min rest period between tests. The highest measurements were taken for the analysis. ${ }^{18}$

Pulmonary function and respiratory muscle strength were measured with a digital spirometry with maximal inspiratory pressure (MIP)/maximal expiratory pressure (MEP) module (Pony FX, COSMED Inc., Rome, Italy). Forced vital capacity (FVC), forced expiratory volume in one second (FEV1), MIP, and MEP values were measured according to the ATS/European Respiratory Society (ERS) criteria. ${ }^{19}$

Single-breath diffusing capacity of the lungs for carbon monoxide (DLCO) was measured using a rapid carbon monoxide and helium analyzer, the HD CPL model computerized system (nSpire Health $^{\mathrm{TM}}$ Inc., Longmont, CO, USA) according to ATS/ERS standards. ${ }^{20}$

Dyspnea severity in daily living of subjects was evaluated by the Modified Medical Research Council scale which consists of five grades that describe the range of dyspnea from none (Grade 0) to complete incapacity (Grade 4). ${ }^{21}$

\section{Statistical analysis}

Statistical analysis was performed using the IBM SPSS version 22.0 software (IBM Corp., Armonk, NY, USA). Quantitative variables were expressed in mean \pm standard deviation (SD) or median (min-max), while qualitative variables were 
expressed in number and percentage. The normal distribution of the data was examined using the Shapiro-Wilk Test. The unpaired Student's t-test and Chi-square tests or Fisher exact tests were used to compare the data of healthy subjects and patients with SSc. Factors associated with balance and frequency of falls were studied by using Pearson's correlation coefficients. To obtain a power of $85 \%$ with a probability of a two-tailed Type I error of 0.05 , a sample of 30 subjects was required in each group to demonstrate a significant difference on the BBS score. ${ }^{8}$ Power analysis was calculated by the G*Power 3.1 program (Heinrich-Heine-Universität Düsseldorf, Düsseldorf, Germany). A $p$ value $<0.05$ was considered statistically significant.

\section{RESULTS}

The general and clinical characteristics of SSc and control group subjects are given in Table 1 . There were no significant differences between the control and SSc groups for age, sex, and BMI (all $\mathrm{p}>0.05$ ). Nine participants (five patients with SSc and four healthy subjects) were former smokers. The individuals who participated in this study had no active smoking and no regular exercise habits for the past year. The mean onset of disease symptoms was $6.6 \pm 4.7$ years in SSc group. Eighteen (60.0\%) patients had diffuse form of disease while 12 (40.0\%) had the limited form.

The results of the balance and history of falls are demonstrated in Table 2. The SSc group showed a significantly higher overall OSI (0.6 \pm 0.5$)$, APSI and MLSI, longer test duration $(51.8 \pm 11.8)$, and lower directional control score $(42.1 \pm 8.0)$ on LOS Index than control group (all, $\mathrm{p}<0.05)$. The SSc group showed significantly lower BBS score $(51.5 \pm 4.9)$ and higher TUG $(8.3 \pm 2.7)$ test duration (all, $p<0.05)$. Also, there was a significant difference in the number of fallers and the frequency of falls between the SSc and control groups (all, p<0.05). The SSc group had significantly lower walking distance of 6MWT, limb muscles strength, pulmonary function test values, respiratory muscle strength, diffusion capacity, and higher dyspnea severity than control group (all, $\mathrm{p}<0.05)$ (Table 3).

Correlations between balance, frequency of falls, and other outcome parameters in SSc group are given in Table 4. Biodex-BS subscales were significantly associated with functional capacity, lower limb muscles strength, MIP\%, MEP\%, DLCO $\%$, and dyspnea severity (all, $p<0.05$ ). Furthermore, Biodex-BS-LOS Index exhibited

\begin{tabular}{|c|c|c|c|c|c|c|c|}
\hline & \multicolumn{3}{|c|}{ SSc group } & \multicolumn{3}{|c|}{ Control group } & \multirow[b]{2}{*}{$p$} \\
\hline & $\mathrm{n}$ & $\%$ & Mean \pm SD & $\mathrm{n}$ & $\%$ & Mean \pm SD & \\
\hline $\begin{array}{l}\text { Sex } \\
\quad \text { Male } \\
\text { Female }\end{array}$ & $\begin{array}{c}6 \\
24\end{array}$ & & & $\begin{array}{c}6 \\
24\end{array}$ & & & 1.000 \\
\hline Age (year) & & & $51.1 \pm 10.6$ & & & $52.4 \pm 8.7$ & 0.110 \\
\hline Height (cm) & & & $162.4 \pm 7.4$ & & & $167.0 \pm 6.5$ & 0.426 \\
\hline Weight (kg) & & & $71.6 \pm 16.2$ & & & $76.4 \pm 14.1$ & 0.407 \\
\hline Body mass index $\left(\mathrm{kg} / \mathrm{m}^{2}\right)$ & & & $26.2 \pm 5.0$ & & & $27.1 \pm 4.0$ & 0.388 \\
\hline Former smokers & 5 & 16.6 & & 4 & 13.3 & & 1.000 \\
\hline Smoking consumption (packet-year) & 1.4 & 3.6 & & 0.98 & 2.70 & & 0.278 \\
\hline Disease duration (year) & 6.6 & 4.7 & & - & & & - \\
\hline Diffuse SSc & 18 & 60.0 & & - & & & - \\
\hline Limited SSc & 12 & 40.0 & & - & & & - \\
\hline Arterial hypertension & 13 & 43.3 & & - & & & - \\
\hline Interstitial lung disease & 16 & 53.3 & & - & & & - \\
\hline Raynaud's phenomenon & 28 & 93.3 & & - & & & - \\
\hline
\end{tabular}


Table 2. Biodex Balance System ${ }^{\mathrm{TM}}$, Berg Balance Scale, and Timed Up and Go test results and history of falls of study groups

\begin{tabular}{|c|c|c|c|c|c|c|c|c|}
\hline & \multicolumn{3}{|c|}{ SSc group } & \multicolumn{3}{|c|}{ Control group } & \multirow[b]{2}{*}{$\mathrm{p}$} & \multirow{2}{*}{$\frac{\% 95 \mathrm{CI}}{\text { Lower/upper bound }}$} \\
\hline & $\mathrm{n}$ & $\%$ & Mean \pm SD & $\mathrm{n}$ & $\%$ & Mean \pm SD & & \\
\hline \multicolumn{9}{|l|}{ Biodex-PS } \\
\hline OSI & & & $0.6 \pm 0.5$ & & & $0.3 \pm 0.1$ & 0.001 & $0.15 / 0.55$ \\
\hline APSI & & & $0.5 \pm 0.2$ & & & $0.3 \pm 0.1$ & 0.005 & $0.09 / 0.28$ \\
\hline MLSI & & & $0.5 \pm 0.4$ & & & $0.1 \pm 0.1$ & 0.001 & $0.18 / 0.55$ \\
\hline \multicolumn{9}{|l|}{ Biodex-limit of stability } \\
\hline Test duration (sec) & & & $51.8 \pm 11.8$ & & & $36.8 \pm 4.8$ & $<0.001$ & $10.36 / 19.70$ \\
\hline Overall percentage & & & $42.1 \pm 8.0$ & & & $67.8 \pm 5.3$ & 0.039 & $-29.20 / 22.19$ \\
\hline Front & & & $45.3 \pm 17.4$ & & & $70.7 \pm 7.9$ & $<0.001$ & $-28.27 /-9.72$ \\
\hline Back & & & $38.7 \pm 12.9$ & & & $65.5 \pm 14.0$ & $<0.001$ & $-38.22 /-5.27$ \\
\hline Right & & & $48.8 \pm 11.8$ & & & $67.3 \pm 7.9$ & 0.049 & $-23.68 /-13.31$ \\
\hline Left & & & $50.9 \pm 13.2$ & & & $70.6 \pm 9.7$ & 0.008 & $-25.69 /-13.70$ \\
\hline Front-right & & & $50.3 \pm 11.0$ & & & $70.0 \pm 8.2$ & $<0.001$ & $-23.75 /-7.62$ \\
\hline Front-left & & & $54.9 \pm 10.4$ & & & $70.7 \pm 7.6$ & 0.069 & $-20.43 / 11.03$ \\
\hline Back-right & & & $40.1 \pm 13.8$ & & & $64.7 \pm 6.4$ & $<0.001$ & $-30.16 /-19.03$ \\
\hline Back-left & & & $38.9 \pm 10.5$ & & & $65.9 \pm 5.3$ & 0.001 & $-31.25 /-22.67$ \\
\hline Berg Balance Scale & & & $51.5 \pm 4.9$ & & & $55.0 \pm 1.3$ & $<0.001$ & $-6.15 /-1.77$ \\
\hline Timed Up and Go (sec) & & & $8.3 \pm 2.7$ & & & $5.4 \pm 0.8$ & $<0.001$ & $1.87 / 3.91$ \\
\hline Subjects with falls & 9 & 30.0 & & 1 & 3.3 & & 0.012 & - \\
\hline Frequency of falls (time/year) & & & $0.43 \pm 0.3$ & & & $0.3 \pm 0.2$ & $<0.001$ & $0.12 / 0.67$ \\
\hline
\end{tabular}

correlation with FEV1\% and FVC\% (all, $\mathrm{p}<0.05$ ). BBS score had correlation with age, frequency of falls, functional capacity, lower limb muscles strength, and dyspnea severity (all, $\mathrm{p}<0.05$ ). The TUG test was significantly associated with age, frequency of falls, functional capacity, lower limb

Table 3. Functional capacity, lower limb muscle strength, pulmonary function, respiratory muscle strength, diffusion capacity, and dyspnea severity results of study groups

\begin{tabular}{|c|c|c|c|c|}
\hline & SSc group & Control group & & $\% 95$ CI \\
\hline & Mean \pm SD & Mean \pm SD & $\mathrm{p}$ & Lower/upper bound \\
\hline Walking distance (m) & $369.7 \pm 97.0$ & $558.5 \pm 50.1$ & 0.018 & $-198.74 /-118.91$ \\
\hline The KE strength $(\mathrm{kg})$ & $6.6 \pm 1.9$ & $18.1 \pm 5.4$ & $<0.001$ & $-13.57 /-9.42$ \\
\hline The HF strength (kg) & $6.9 \pm 2.1$ & $13.6 \pm 3.1$ & $<0.001$ & $-8.22 /-5.21$ \\
\hline The AE strength $(\mathrm{kg})$ & $6.4 \pm 1.8$ & $13.7 \pm 3.9$ & 0.001 & $-8.85 /-5.70$ \\
\hline FVC (\% predicted) & $75.2 \pm 14.8$ & $94.4 \pm 6.6$ & $<0.001$ & $-24.51 /-9.95$ \\
\hline FEV1 (\% predicted) & $76.3 \pm 11.4$ & $93.4 \pm 5.1$ & $<0.001$ & $-22.78 /-7.41$ \\
\hline MIP (\% predicted) & $54.4 \pm 18.4$ & $99.6 \pm 17.9$ & 0.021 & $-57.51 /-32.96$ \\
\hline MEP (\% predicted) & $56.9 \pm 14.3$ & $118.9 \pm 14.7$ & 0.007 & $-71.40 /-50.66$ \\
\hline DLCO (\% predicted) & $63.5 \pm 11.1$ & $95.8 \pm 7.2$ & $<0.001$ & $-39.08 /-25.51$ \\
\hline mMRC dyspnea & $2.78 \pm 0.9$ & $0.1 \pm 0.3$ & $<0.001$ & $2.28 / 2.98$ \\
\hline
\end{tabular}

SSc: Systemic sclerosis; CI: Confidence interval; SD: Standard deviation; KE: Knee extensor; HF: Hip flexor; AE: Ankle extensor; FVC: Forced vital capacity; FEV1: Forced expiratory volume in one second; MIP: Maximal inspiratory pressure; MEP: Maximal expiratory pressure; DLCO: Diffusing capacity for carbon monoxide; mMRC: Modified Medical Research Council.. 
Table 4. Correlations between balance, frequency of falls, and other outcome parameters in systemic sclerosis patients

\begin{tabular}{|c|c|c|c|c|c|}
\hline & \multirow[b]{2}{*}{ Frequency of falls (rho) } & \multirow[b]{2}{*}{ BBS (rho) } & \multirow[b]{2}{*}{ TUG (rho) } & \multicolumn{2}{|c|}{ Biodex Balance System } \\
\hline & & & & LOS-OP (rho) & PS-OSI (rho) \\
\hline Age (year) & 0.330 & $-0.419^{*}$ & $0.396^{*}$ & -0.184 & 0.081 \\
\hline Body mass index $\left(\mathrm{kg} / \mathrm{m}^{2}\right)$ & 0.100 & -0.345 & 0.158 & 0.171 & 0.179 \\
\hline Disease duration (year) & 0.295 & -0.024 & 0.322 & -0.275 & 0.008 \\
\hline Frequency of falls (times/year) & - & $-0.750^{* * *}$ & $0.807^{* * *}$ & $-0.696^{* * *}$ & $0.759^{* * *}$ \\
\hline Walking distance (m) & $-0.819^{* * * *}$ & $0.744^{* * *}$ & $-0.827^{* * * *}$ & $0.606^{* * * *}$ & $-0.524^{* *}$ \\
\hline The KE strength (kg) & $-0.667^{* * * *}$ & $0.413^{*}$ & $-0.506^{* *}$ & $0.877^{* * * *}$ & $-0.560^{* * *}$ \\
\hline The HF strength (kg) & $-0.667^{* * * *}$ & $0.469^{* * *}$ & $-0.550^{* *}$ & $0.861^{* * * *}$ & $-0.582^{* * * *}$ \\
\hline The AE strength (kg) & $-0.680^{* * * *}$ & $0.475^{* *}$ & $-0.537^{* *}$ & $0.881^{* * * *}$ & $-0.610^{* * * *}$ \\
\hline FVC (\% predicted) & -0.321 & 0.205 & -0.266 & $0.435^{*}$ & -0.240 \\
\hline FEV1 (\% predicted) & $-0.390^{*}$ & 0.194 & -0.316 & $0.420^{*}$ & -0.313 \\
\hline MIP (\% predicted) & $-0.378^{*}$ & 0.296 & $-0.445^{*}$ & $0.514^{* *}$ & $-0.351^{*}$ \\
\hline MEP (\% predicted) & $-0.615^{* * *}$ & 0.346 & $-0.496^{* *}$ & $0.634^{* * * *}$ & $-0.533^{* *}$ \\
\hline DLCO (\% predicted) & $-0.410^{*}$ & 0.141 & -0.244 & $0.547^{* *}$ & $-0.478^{* *}$ \\
\hline mMRC dyspnea score & $0.704^{* * * *}$ & $-0.553^{* * *}$ & $0.549^{* * *}$ & $-0.529^{* * *}$ & $0.565^{* * *}$ \\
\hline
\end{tabular}

muscles strength, MIP\%, MEP\%, and dyspnea severity. There was a significant correlation between frequency of falls and postural balance (both laboratory and clinical tests), functional capacity, lower limb muscles strength, FEV1\%, $\mathrm{MIP} \%, \mathrm{MEP} \%$, DLCO\%, and dyspnea severity in the SSc group (all, $\mathrm{p}<0.05$ ).

\section{DISCUSSION}

According to the results of our study, the SSc group showed postural balance impairment and higher fall risk than control group and these were significantly associated with functional capacity, lower limb muscles strength, pulmonary function, respiratory muscle strength, diffusion capacity, and dyspnea severity.

Postural balance entails a complete interaction between the neural and the musculoskeletal system which includes biomechanical relationships between the body segments. Postural balance impairment is seen in many rheumatoid, pulmonary, and neurological diseases which is stated as one of the most important complications since it is associated with loss of functional independence and possibility of falls. ${ }^{9,10,22}$ However, only a few previous studies have evaluated postural balance in $\mathrm{SSc}$ and the results are controversial. ${ }^{7,8}$ Similar to the study of Giacomini et al., ${ }^{7}$ we observed a significant difference in postural balance between the SSc and control groups. Contrary to our study results, Lima et al. ${ }^{8}$ stated that they did not find any significant difference in any of the variables of postural balance in SSc and control groups. We think that the results may be inconsistent because the average age of the mentioned study was younger than our participants and also the exclusion criteria and the methods used in balance assessment were different from ours. While the number of studies evaluating postural balance in SSc is scarce and insufficient in the literature, another important point of the current study is that it evaluated postural balance with both well-validated clinical and laboratory tests. We used the Biodex-BS as a laboratory test because of its high validity and reliability. ${ }^{14}$ The related literature pointed out that TUG and BBS tests, which are reliable and easily applicable in the clinical balance assessment in neurological, musculoskeletal and other rheumatoid diseases, are widely used. ${ }^{16,23}$ Similar to our results, Giacomini et al. ${ }^{7}$ reported 
an increased postural instability (increased body sway) in patients with $\mathrm{SSc}$ in anteroposterior and mediolateral axis direction on upright stance compared with healthy controls by using the Biodex-BS. We observed that the SSc group had increased anteroposterior and mediolateral sway in postural stability assessment as well as decreased directional control score and increased test duration of Biodex-BS-LOS Index compared to the control group. The main result of impaired balance is associated with hospitalizations, mortality, disability, and impairment in functional and daily life activity. Furthermore, the incidence of falls escalades in patients with joint problems such as osteoarthritis, rheumatoid arthritis, and ankylosing spondylitis regardless of age factor. ${ }^{11,24,25}$ However, when we searched the literature, we could not find any study evaluating fall risk and related factors in patients with SSc. Similar to other rheumatoid disease patients, $30 \%$ of patients with SSc had a history of falls at least once in the past year in our study. In our study, the fall frequency of patients with SSc was significantly higher than healthy subjects even though they were age matched. In line with these results, we think that postural balance and fall risk should be evaluated from the early period and treatment strategies should be included in rehabilitation programs for the continuity of the functional independence of patients with SSc.

Systemic sclerosis is a multisystemic disease which can potentially affect functional capacity including walking and jogging and may lead to cardiopulmonary involvement, osteoarticular problems, and musculoskeletal disorder. ${ }^{26}$ In addition, factors such as muscle changes due to inflammatory and non-inflammatory myopathies, joint contractures, disease chronicity, and drugrelated muscle disease may cause skeletal muscle weakness and atrophy in patients with $\mathrm{SSc}^{2}$ In accordance with other authors, we also found that functional capacity and lower limb muscle strength of SSc group were significantly lower than control group. ${ }^{26-28}$ Appropriate sensory reactions and sufficient muscle strength in the lower extremities are required in maintaining postural control and reducing postural sway; both of these are also important factors in preventing people from falling over. ${ }^{29}$ Recent studies have found that there is postural balance impairment and thus increased fall risk during dynamic activities in many diseases, and showed that these balance deficiencies are associated with lower limb muscle weakness, low levels of physical activity, and functional capacity in these individuals. ${ }^{29,30}$ Based on these studies conducted in other patient groups, we investigated the relationship of lower limb muscle strength and functional capacity with postural balance and frequency of falls in patients with SSc. Our study is important for being the first study on this subject and revealing a significant correlation between functional capacity, lower extremity muscle strength and postural balance, and frequency of falls in patients with SSc. Therefore, we think that regular exercise programs and physical activity recommendations focusing on increasing muscle strength and functional capacity should be included in the treatment strategies to prevent the fall risk and maintain postural balance in patients with SSc.

Increased respiratory demand may induce neural drive to diaphragm and activate superficial trunk muscles which results in increased trunk stiffness in healthy subjects. Moreover, increased respiratory demand was associated with either increased ankle movement or increased coherence between respiratory motion of the chest and movement of hip and knee. Changes in the chest, trunk, and lower limb movements with increased trunk stiffness reduce an individual's ability to control balance. ${ }^{31}$ Similarly, increased respiratory demand in diseases with respiratory problems may affect postural balance with this mechanism. ${ }^{32}$ Therefore, we think that factors such as increased respiratory demand due to vascular damage, decreased respiratory muscle strength, joint, and muscle involvement due to fibrosis formation may cause indirectly increased body sway in patients with $\mathrm{SSc}$, similar to the mechanisms in respiratory diseases. Compatible with the results of previous studies, SSc group had significantly lower spirometry results, respiratory muscle strengths, and diffusion capacities than control group in this study. ${ }^{8,27,33}$ These parameters are actually related to lung involvement was were associated with postural balance and fall risk. To our knowledge, there was only one study investigating the relationship between lung involvement and postural balance, stating that the FVC/DLCO ratio was associated with postural control and balance. ${ }^{8}$ Still, the relationship between lung involvement and 
postural balance and possible mechanisms are unknown and studies on this subject are needed.

Dyspnea is one of the most common activity-limiting symptoms, as it is strongly related to the intensity of the activity performed in respiratory disease. For this reason, it causes decreased physical activity by stages. ${ }^{34}$ In addition, dyspnea is seen in patients with SSc due to ILD, $\mathrm{PAH}$, and skin-tightening, limiting the movement and chest expansion. ${ }^{33}$ In our SSc group, dyspnea was a common symptom. In addition, dyspnea severity was significantly associated with postural balance and frequency of falls. Decreased level of physical activity and functional capacity with increased dyspnea severity may have affected indirectly the postural balance and the fall risk in SSc group. Therefore, we recommend evaluating dyspnea severity in addition to the routine assessment of pulmonary function tests and diffusion capacity to evaluate patients' lung involvement and to determine the effectiveness of the maintenance of postural balance.

The strength of this study is that it is the first study to evaluate the fall risk and related factors in patients with SSc. In addition, this study is important in terms of evaluating postural balance comprehensively with clinical and laboratory tests, which are valid and reliable methods, and comparing the results with age-, sex-, and BMI-matched healthy volunteers. Moreover, this study is the first to investigate the relationship between postural balance and functional capacity, lower limb muscle strength, respiratory muscle strength, and dyspnea severity. However, despite its strong sides, there are some limitations as well. Firstly, we did not examine intrinsic factors such as depression, malnutrition, and medication and extrinsic factors such as residential area and housing type which may be associated with the fall risk and postural balance in patients with SSc. Secondly, due to the cross-sectional planning of the study, the cause-effect relationship cannot be given precisely. Still, this study provides remarkable results to pave the way for further clinical studies and rehabilitation strategies in this field since the literature is insufficient in terms of evaluating the postural balance, fall risk, and related factors in patients with $\mathrm{SSc}$.

In conclusion, this study shows that patients with SSc have impairment of postural balance and high fall risk. Impaired postural balance and increased fall frequency were associated with poorer functional capacity, decreased lower limb muscle strength, and lung involvement in our SSc group. Therefore, our results underline that postural balance impairment and fall risk should be assessed in patients with SSc. Furthermore, the evaluation of functional capacity, muscle strength, and lung involvement may highlight those who have impaired postural balance and higher fall risk earlier. We suggest that treatment strategies aimed at maintaining postural balance and preventing falls should be added to the routine rehabilitation programs of patients with SSc. However, additional longitudinal studies are needed to confirm our results.

\section{Declaration of conflicting interests}

The authors declared no conflicts of interest with respect to the authorship and/or publication of this article.

\section{Funding}

The authors received no financial support for the research and/or authorship of this article.

\section{REFERENCES}

1. Denton CP, Khanna D. Systemic sclerosis. Lancet 2017;390:1685-99.

2. Ranque $\mathrm{B}$, Bérezné $\mathrm{A}$, Le-Guern $\mathrm{V}$, Pagnoux $\mathrm{C}$, Allanore Y, Launay D, et al. Myopathies related to systemic sclerosis: a case-control study of associated clinical and immunological features. Scand J Rheumatol 2010;39:498-505.

3. Gohari Moghadam K, Gharibdoost F, Parastandechehr G, Salehian P. Assessments of pulmonary involvement in patients with systemic sclerosis. Arch Iran Med 2011;14:22-6.

4. Lima TR, Guimarães FS, Silva LA, Silva DP, Menezes SL, Lopes AJ. Relationship between functional capacity, joint mobility and pulmonary function in patients with systemic sclerosis. J Bodyw Mov Ther 2015;19:17-24.

5. Schade L, Paiva Edos S, Müller Cde S. Skeletal and cardiac muscles involvement in systemic sclerosis. Rev Bras Reumatol 2011;51:309-10, 313.

6. Barrera P, den Broeder AA, van den Hoogen FH, van Engelen BG, van de Putte LB. Postural changes, dysphagia, and systemic sclerosis. Ann Rheum Dis 1998;57:331-8.

7. Giacomini PG, Zoli A, FerraroS, Raffaldi AV, Bartolozzi F, Di Girolamo S. Evaluation of abnormalities of orthostatic postural control in systemic sclerosis. Clin Exp Rheumatol 2005;23:297-302. 
8. Lima TR, Guimarães FS, Neves RS, Menezes SL, Lopes AJ. Scleroderma: Assessment of posture, balance and pulmonary function in a cross-sectional controlled study. Clin Biomech (Bristol, Avon) 2015;30:438-43.

9. Pompeu JE, Romano RS, Pompeu SM, Lima SM. Static and dynamic balance in subjects with ankylosing spondylitis: literature review. Rev Bras Reumatol 2012;52:409-16.

10. de Castro LA, Ribeiro LR, Mesquita R, de Carvalho DR, Felcar JM, Merli MF, et al. Static and Functional Balance in Individuals With COPD: Comparison With Healthy Controls and Differences According to Sex and Disease Severity. Respir Care 2016;61:1488-96.

11. Brenton-Rule A, Dalbeth N, Menz HB, Bassett $\mathrm{S}$, Rome K. Are Foot and Ankle Characteristics Associated With Falls in People With Rheumatoid Arthritis? A Prospective Study. Arthritis Care Res (Hoboken) 2017;69:1150-5.

12. Duarte M, Freitas SM. Revision of posturography based on force plate for balance evaluation. Rev Bras Fisioter 2010;14:183-92.

13. van den Hoogen F, Khanna D, Fransen J, Johnson SR, Baron M, Tyndall A, et al. 2013 classification criteria for systemic sclerosis: an American College of Rheumatology/European League against Rheumatism collaborative initiative. Arthritis Rheum 2013;65:2737-47.

14. Dawson N, Dzurino D, Karleskint M, Tucker J. Examining the reliability, correlation, and validity of commonly used assessment tools to measure balance. Health Sci Rep 2018;1:e98.

15. Browne W, Nair BKR. The Timed Up and Go test. Med J Aust 2019;210:13-4.e1.

16. Bennie S, Bruner K, Dizon A, Fritz H, Goodman B, Peterson S. Measurements of balance: comparison of the Timed "Up and Go" test and Functional Reach test with the Berg Balance Scale. J Phys Ther Sci 2003;15:93-7.

17. ATS Committee on Proficiency Standards for Clinical Pulmonary Function Laboratories. ATS statement: guidelines for the six-minute walk test. Am J Respir Crit Care Med 2002;166:111-7.

18. Pasco JA, Stuart AL, Holloway-Kew KL, Tembo $\mathrm{MC}$, Sui SX, Anderson KB, et al. Lower-limb muscle strength: normative data from an observational population-based study. BMC Musculoskelet Disord 2020;21:89.

19. Miller MR, Hankinson J, Brusasco V, Burgos F, Casaburi R, Coates A, et al. Standardisation of spirometry. Eur Respir J 2005;26:319-38.

20. Roca J, Rodriguez-Roisin R, Cobo E, Burgos F, Perez J, Clausen JL. Single-breath carbon monoxide diffusing capacity prediction equations from a Mediterranean population. Am Rev Respir Dis 1990;141:1026-32.

21. Nishiyama O, Taniguchi H, Kondoh Y, Kimura T, Kato K, Kataoka K, et al. A simple assessment of dyspnoea as a prognostic indicator in idiopathic pulmonary fibrosis. Eur Respir J 2010;36:1067-72.

22. Chen L, Lo WL, Mao YR, Ding MH, Lin Q, Li H, et al. Effect of Virtual Reality on Postural and Balance Control in Patients with Stroke: A Systematic Literature Review. Biomed Res Int 2016;2016:7309272.

23. Zonzini Gaino J, Barros Bértolo M, Silva Nunes C, de Morais Barbosa C, Sachetto Z, Davitt M, et al. Disease-related outcomes influence prevalence of falls in people with rheumatoid arthritis. Ann Phys Rehabil Med 2019;62:84-91.

24. Tsonga T, Michalopoulou M, Malliou P, Godolias G, Kapetanakis S, Gkasdaris G, et al. Analyzing the History of Falls in Patients with Severe Knee Osteoarthritis. Clin Orthop Surg 2015;7:449-56.

25. Dursun N, Sarkaya S, Ozdolap S, Dursun E, Zateri C, Altan L, et al. Risk of falls in patients with ankylosing spondylitis. J Clin Rheumatol 2015;21:76-80.

26. Deuschle K, Weinert K, Becker MO, Backhaus M, Huscher D, Riemekasten G. Six-minute walk distance as a marker for disability and complaints in patients with systemic sclerosis. Clin Exp Rheumatol 2011;29(2 Suppl 65):S53-9.

27. Lima TR, Guimarães FS, Carvalho MN, Sousa TL, Menezes SL, Lopes AJ. Lower limb muscle strength is associated with functional performance and quality of life in patients with systemic sclerosis. Braz J Phys Ther 2015;19:129-36.

28. Poole JL, Brandenstein J. Difficulty with daily activities involving the lower extremities in people with systemic sclerosis. Clin Rheumatol 2016;35:483-8.

29. Janssens L, Brumagne S, McConnell AK, Claeys $\mathrm{K}$, Pijnenburg $\mathrm{M}$, Burtin $\mathrm{C}$, et al. Proprioceptive changes impair balance control in individuals with chronic obstructive pulmonary disease. PLoS One 2013;8:e57949.

30. Stanmore EK, Oldham J, Skelton DA, O'Neill T, Pilling M, Campbell AJ, et al. Risk factors for falls in adults with rheumatoid arthritis: a prospective study. Arthritis Care Res (Hoboken) 2013;65:1251-8.

31. Hodges PW, Gurfinkel VS, Brumagne S, Smith TC, Cordo PC. Coexistence of stability and mobility in postural control: evidence from postural compensation for respiration. Exp Brain Res 2002;144:293-302.

32. Smith MD, Chang AT, Hodges PW. Balance recovery is compromised and trunk muscle activity is increased in chronic obstructive pulmonary disease. Gait Posture 2016;43:101-7.

33. Thombs BD, Hudson M, Bassel M, Taillefer SS, Baron M; Canadian Scleroderma Research Group. Sociodemographic, disease, and symptom correlates of fatigue in systemic sclerosis: evidence from a sample of 659 Canadian Scleroderma Research Group Registry patients. Arthritis Rheum 2009;61:966-73.

34. Reardon JZ, Lareau SC, ZuWallack R. Functional status and quality of life in chronic obstructive pulmonary disease. Am J Med 2006;119(10 Suppl 1):32-7. 